\title{
THE EFFECT OF ESSENTIAL OILS ON QUALITY AND SAFETY PARAMETERS OF MEAT DURING ITS STORAGE
}

\author{
Aleh U. Shkabrou*, Viktar D. Raznichenka, Lidziya Y. Kharkevich \\ Belarusian State University of Food and Chemical Technologies, Mogilev, Republic of Belarus
}

Keywords: essential oils, autolytic processes, specific electrical conductivity, histological structural changes, bactericidal efficiency

\begin{abstract}
This article researches the basic principles of mechanism for finding the concentrations of essential oils (EO) which are efficient for antimicrobial action, when used as a natural alternative to synthetic analogues. The effect of EO of rosemary, sage, garlic, laurel, cloves, basil and thyme on the structural components of meat, its physical and chemical, organoleptic and microbiological quality indices was studied. The effect of EO on duration of microorganisms' growth phases is analyzed. It is shown that the reasonable concentration of the essential-oil mixture (EOM) is equal to $0.1 \%$, since at this concentration the optimal inhibition of saprophytic microflora was provided with satisfactory organoleptic quality indices ("taste peculiar for this type of product", "pleasant fragrance", "spicy aroma"). The analysis of histological structural changes in muscle tissue showed that application of EOM slows down autolytic processes, which correlates with the data obtained in research of the specific electrical conductivity in water extracts from the muscle tissue. The autolysis process in the control samples was more intensive in comparison with the experimental samples stored in the EOM. Thus, by 84th hour of storage in the control sample the basophilic staining of the samples slices was observed, as well as almost complete disappearance of the striation of muscle fibers. In the muscle tissue slices the disintegration of individual fragments into myofibrils, and myofibrils into sarcomeres, was observed in form of a granular mass, sometimes enclosed in endomysium. The meat fibers were deformed and their separation was observed. The same changes with the studied samples stored in the EOM occurred only after 204 hours of storage. The above studies of changes in the specific electrical conductivity of water extract from meat during storage showed the presence of complexes of EOM components formed with proteins and lipids of muscle tissue. The obtained data are confirmed by histological studies. Thus, the use of EOM allowed elongation of the cold storage period of semi-finished natural lump products by 2.6 times, which proves the practical benefits of its use in the meat-processing industry.
\end{abstract}

\section{Introduction}

The annual increase in consumption of meat and meat products makes it necessary to develop logistics, transport networks and new technologies that ensure the due quality of the product throughout the entire chain of its life cycle. Meat losses after production are estimated at $10 \%$ approximately. It should be noted that microbiological spoilage is the main contributor to these losses, along with lipid oxidation and enzymatic spoilage. Despite the improvement of production methods, despite introduction and implementation of hygienic and control measures in the food industry, every year there are cases of food diseases caused by food that does not meet the safety requirements. According to WHO [1] data, every year 600 million people, or almost one of ten people in the world, get food-poisoned after eating contaminated food, 420,000 of them die, including 125,000 children under age of five. $15 \%$ of such cases are caused by the use of substandard quality meat products.

This way, the relatively short shelf life and the growing demand for high-quality and safe meat products lead to the need for new technologies which are able to extend the shelf life while maintaining a high level of quality. In this regard, in order to increase the shelf life of meat products, many synthetic and natural components are used nowa- days. The growing interest of manufacturers and consumers in natural food additives contributes to the practical value of this study and to the search for a natural alternative to synthetic analogues. These components must form the necessary parameters, indices and factors of meat products quality and meet the food safety requirements.

One possible solution to this problem is application of $\mathrm{EO}$ as natural preservatives in manufacture of food products, in particular: meat and meat products. It is known [2] that essential oils feature the properties of natural additives with a wide spectrum of action, for example, they feature antimicrobial, antiviral, antiparasitic, antifungal, antioxidant etc. properties in relation to many pathogens, such as Pseudomonas, Acinetobacter-Moraxella, Enterobacteriaceae, Fusarium, Mucor, Candida, Torulopsis, etc., which were previously studied by a wide range of researchers

The authors [3] studied and considered the issue of assessing the antimicrobial effect of essential oils in certain combinations on food pathogens. The research shows that the active components of essential oils can be divided into four groups according to their chemical structure: terpenes, such as lemon EO; terpenoids, such as jasmine essential EO; phenylpropenes, such as vanilla EO; and others, such as mustard EO, which contains allyl isothiocyanate as the active agent. At the same time, mustard EO showed the 
highest antimicrobial activity against all tested pathogens with the largest diameter of the growth inhibition zone.

It was shown in research [4] that the combination of EO of rosemary and eucalyptus can be considered as the most efficient against pathogenic microorganisms when used in the food industry and medicine. It is also shown that the EO concentration of $40 \%$ is the most efficient and the inhibition zone increases along with the increase of concentration.

In the review [5] the main mechanisms of EO components effect on the microbial cell were considered. Special attention is paid to the effect of phenolic compounds on permeability of microbial cells. Phenolic compounds damage the cytoplasmic membrane, and disrupt the mechanism of ATP generation and driving proton force.

The authors [6] showed that EO components, like carvacrol and thymol, have noticeable disintegration action on cells walls, as evidenced by their enhancing effect on absorption of 1-N-phenylnaphthylamine and on release of lipopolysaccharides, as well as increasing of sensitivity to detergents. The breakdown of cytoplasmic membrane integrity leads to excessive loss of metabolites and enzymes from the cell and loss of its viability. These compounds also inhibit bacterial growth at the same concentrations which are necessary for cell wall disintegration, and increase the permeability of the ATP cytoplasmic membrane.

In [7], the destruction of membrane proteins of pathogenic cells Bacillus cereus under the effect of carvacrol was studied in detail. Carvacrol is the main active antibacterial component in $\mathrm{EO}$ of thyme and oregano. It increases permeability of the cell membrane to potassium ions. Potassium ion is an important cation for vegetative bacterial cell; it is involved in several key biochemical processes of bacterial cells. This ion plays an important role in activating cytoplasmic enzymes, maintaining turgor pressure, and regulating $\mathrm{pH}$ of cell. The loss of potassium ions is the first indicator of bacteria membrane damage. Inhibition of range of enzymes due to loss of basic ions leads to loss of cell turgor, violation of DNA synthesis, decrease of cell metabolic activity, etc.

As described by the authors of the research [8], carvacrol makes the cell membrane excessively permeable to potassium and hydrogen ions, and inhibits the synthesis of ATP due to violation of chemiosmosis process, which can lead to loss of activity of cellular transport of granulation and coagulation of cytoplasm.

The activity of $\mathrm{EO}$ varies within wide range depending on initial plant raw material, chemical composition, extraction methods, and many other factors. The composition, concentration, and ratio of the chemical components also determine the biological effect of EO.

The interaction between antimicrobial substances in their combination can have three different results: synergistic, additive, or antagonistic. Synergy occurs when a mixture of two antimicrobial compounds has antimicrobial activity greater than the sum of the activities of the individual components. An additive effect is obtained when a mixture of antimicrobial substances has a combined effect equal to the sum of the individual activities of the compounds. Antagonism occurs when a mixture of antimicrobial compounds has a combined effect less than with a separate application.

Despite the large amount of literature which covers the study of the antimicrobial properties of essential oils, the results in vitro are not easy to compare with results obtained in vivo when using them as preservatives for meat. However, studies of rosemary, cinnamon, lavender, sage, garlic, oregano and ginger essential oils have shown positive results regarding their ability to act as food preservatives $[2,9]$.

Essential oils tend to be more efficient when they come into direct contact with organisms, so the practical interest is to create a mechanism for finding concentrations of essential oils that are efficient to achieve an antimicrobial action. However, direct contact with meat can affect its organoleptic quality indices through structural and chemical reactions or interactions. Essential oils tend to have an intense aroma even at low concentrations and, if used incorrectly, can negatively affect the consumer properties of food products.

Due to the possible interaction of essential oil components with the cellular structures of meat, a higher concentration of essential oils is usually required to achieve an antimicrobial effect. Along with that the application of EO in high concentrations to achieve the required antimicrobial activity causes negative changes in the quality, taste and smell of meat.

In industrial production scale, $\mathrm{EO}$ as a meat preservative is very difficult and expensive to be used directly, while ensuring sufficient control of their quality and quantity. The use of active packaging is promising perspective, in which EO can either be incorporated into the packaging materials and then diffuse into the meat, or released on the meat by evaporation in the free space between the packaging and the meat. Thus, the use of Rosmarinus officinalis essential oil, as part of the active packaging in amount of $4 \%$, inhibits the development of putrid processes caused by bacteria (including Enterobacteriaceae and Brochothrix thermosphacta), and formation of such substances like cadaverine [2].

The authors [10] proved that use of special coatings with EO in packaging can reduce the undesirable effects on the taste of the product. Use of such active packaging also allows extending the $\mathrm{EO}$ effect on the product due to its slow release effect.

The research [11] shows the efficiency of application of chitosan and whey protein films soaked with nanocapsulated $2 \%$ garlic essential oil for extension of the shelf life of chilled sausage in vacuum packaging. Based on the analysis of microbiological and lipid stability of sausages, these active films slowed down the oxidation of lipids and the growth of main groups of microorganisms that cause spoilage. 
To assess the effect of $\mathrm{EO}$ on quality of meat it is necessary to use methods that allow assessment of the physical and chemical state of meat raw materials.

It is proved that the study of specific electrical conductivity of muscle tissue by both direct and indirect methods is promising way for assessing the condition of pork during its storage and subsequent processing [12]. The authors proved the effect of morphological composition, various methods of technological processing, as well as the effect of food additives use on specific electrical conductivity [13].

The value of the specific electrical conductivity is directly related to the concentration of ions in the solution, to their nature and mobility. The change in electrical conductivity is also an indicator of the cell membranes breakdown in muscle tissue cells that retain fluid within and outside of the cells. In muscle tissue with intact cell membranes, a low electrical conductivity value is observed, which increases with an increase of water content in the intercellular space [14].

However, nowadays essential oils and their compounds are used in meat products only to limited extent. One of the reasons for this is the insufficient study of the essential oils effect on meat during its storage.

Therefore, in order to assess the degree of EO effect on meat, it was considered appropriate to conduct researches on EOM efficiency, as well as histological and structural, microbiological and physical and chemical parameters of meat during its storage.

\section{Materials and methods}

Raw meat. Chilled pork cutlet meat was used as a raw material. The sample was taken within the production environment of a meat processing enterprise in the Republic of Belarus. Sampling and preparation of samples for study was carried out according to GOST $7269-2015^{1}$ and GOST R51447-99².

To prepare the samples, a liner soaked with essentialoils mixture (EOM), was placed on the bottom of a sealed glass container. The required amount of raw meat was placed in such a way as to ensure that it did not come into direct contact with the liner. The container was hermetically sealed.

Containers with meat samples were stored at a temperature of $0{ }^{\circ} \mathrm{C}$ to $4{ }^{\circ} \mathrm{C}$ and relative humidity of $85 \%$. The samples were examined on $0,36,60,84,156,204^{\text {th }}$ hour of meat storage.

Determination of threshold concentration of EOM. The threshold concentration of EOM was selected on the grounds of results obtained from analysis of data on minimum inhibitory concentration (MIC) of EOM and the determination of threshold concentration of EOM by organoleptic parameters.

${ }^{1}$ GOST 2015-7269 "Meat. Methods of sampling and organoleptic methods of freshness test" Moscow: Standartinform, 2019. - 14 p. (In Russian)

${ }^{2}$ GOST R51447-99 "Meat and meat products. Methods of primary sampling” Moscow: Standartinform, 2014. - 8 p. (In Russian)
For analysis of the MIC EOM, a bacterial suspension was prepared with a concentration of microbial cells of $1 \times 10^{8} \mathrm{CFU} / \mathrm{ml}$, (0.5 units according to the McFarland turbidity standard). The concentration of microbial cells was determined indirectly using the PE-5400 VI photoelectric colorimeter measuring the optical density of solutions, which was equal to $0.08-0.1$. The obtained suspension was diluted with meat-peptone broth (MPB) to obtain a concentration of microbial cells of $1 \times 10^{6} \mathrm{CFU} / \mathrm{ml}$, which corresponds to the indices of old cutlet meat according to the Unified Sanitary-Epidemiological and Hygienic Requirements for food products (commodities) subject to sanitary-epidemiological supervision (control) ${ }^{3}$.

$100 \mathrm{~cm}^{3}$ of the prepared bacterial suspension was added to the sterile flasks and EOM was added until a certain concentration was reached $(0.01 \% ; 0.05 \% ; 0.1 \% ; 0.5 \%)$. The flasks were hermetically sealed and shaken on a SHR-1D laboratory shaker for 6 hours at $20^{\circ} \mathrm{C}$. At the end of shaking, $0.1 \mathrm{~cm}^{3}$ of the suspension was inoculated on sterile GRM-agar culture media from each flask and evenly distributed over the surface of medium. Petri dishes with crops were incubated at $37^{\circ} \mathrm{C}$ for 24 hours. After counting the grown colonies of microorganisms, the number of colony-forming units $\mathrm{CFU} / \mathrm{ml}$ was determined and the results were compared with the value of the concentration of microbial cells in the control sample $\left(1 \times 10^{6} \mathrm{CFU} / \mathrm{ml}\right)$.

In order to determine the threshold concentration of EOM in a food product on the organoleptic basis, samples of pork cutlets were prepared in accordance with the collection of recipes with application of OEM in following amounts: $0 \%$ (control sample), $0.01 \%$ and $0.1 \%$. Upon reaching the culinary (edible) readiness, the samples were evaluated according to the following organoleptic parameters: taste peculiar for this type of product, medicinal aroma, spicy fragrance, pleasant smell, hot taste, sour aftertaste (GOST 31986-2012 ${ }^{4}$ ).

Definition of total viable count - i. e. quantity of mesophilic aerobic and facultative anaerobic microorganisms (QMAFAnM).

Definition of quantity of mesophilic aerobic and facultative anaerobic microorganisms (QMAFAnM) and bacterioscopic examination of meat was carried out according to GOST 10444.15-945.

Study of the histological structure of meat. Histological examination of meat samples was carried out in accordance with the GOST R31479-2012 ${ }^{6}$ and GOST 19496-20137

\footnotetext{
${ }^{3}$ Unified sanitary-epidemiological and hygienic requirements for products (goods) subject to sanitary-epidemiological supervision (control). Decision of the Council of the Eurasian economic Commission of October 28, 2010, № 299. Moscow, 2010. (In Russian)

${ }^{4}$ GOST 31986-2012 "Public catering service. Method of sensory evaluation of catering products" Moscow: Standartinform, 2019. - 15 p. (In Russian)

${ }^{5}$ GOST 10444.15-94." Food products. Methods for determination of quantity of mesophilic aerobes and facultative anaerobes" Moscow: Standartinform, 2010. $-7 \mathrm{p}$.

${ }^{6}$ GOST R31479-2012 "Meat and meat products. Method of histological identification of composition" Moscow: Standartinform, 2019. - $11 \mathrm{p}$.

${ }^{7}$ GOST 19496-2013 "Meat and meat products. The method of histological investigation" Moscow: Standartinform, 2019. - 12 p.
} 
Determination of the specific electrical conductivity. To determine the value of the specific electrical conductivity of meat, an aqueous extract was prepared in a ratio of 1:10, for which the sample was carefully chopped, placed in a cylindrical vessel of $100 \mathrm{ml}$ and extracted with distilled water on a laboratory shaker SHR-1D for 30 minutes at a temperature of $20^{\circ} \mathrm{C}$. The resulting extract was filtered through a folded paper filter. The electrical conductivity of $10 \%$ of the water extract of meat was determined at a fixed temperature by OrionStarA112 conductivity meter with Orion $011050 \mathrm{MD}$ cell.

\section{Results and discussion}

As the essential oils included in the EOM may have different inhibitory activity, it was considered appropriate to determine the inhibitory activity of each EO separately and as part of an essential-oil mixture at a concentration of $0.1 \%$ EOM was compiled on the basis of organoleptic quality indices that are most suitable for its application in production of meat products (Figure 1).

From the data presented in Figure 1, it is obvious that the efficiency of EO in its pure form in amount of $0.1 \%$ widely varied (from $40.00 \%$ for EO of garlic to $99.76 \%$ for EO of thyme). For most of the studied EOs, the bactericidal efficiency ranged from $69.06 \%$ (for EO of clove) to $82.09 \%$ (for EO of basil). The bactericidal efficiency of EOM exceeded 70\%. According to the obtained results, it is reasonable to state the additive effect of $\mathrm{EO}$ as mixture.

In order to determine the concentration of EOM in the modified gas medium at a meat storage temperature from $0{ }^{\circ} \mathrm{C}$ to $4{ }^{\circ} \mathrm{C}$, studies were conducted to determine the minimum inhibitory concentration (MIC) and organoleptic parameters of meat quality.

When determining the MIC, the method of serial dilutions was used. Essential oils, that are part of EOM, were used as inhibitory agents.

The following EOM concentrations were used for serial dilution: $0 \%, 0.01 \%, 0.05 \%, 0.1 \%$, and $0.5 \%$. The dependence of the number of colony forming units on concentration of EOM is shown in the Figure 2 below.

From the data presented in Figure 2, it is obvious that MIC50 (concentration of EOM, to which 50\% of the studied strains are sensitive) and MIC90 (concentration of EOM, to which $90 \%$ of the studied strains are sensitive) for a mixture of essential oils varied within the range of $0.1-0.5 \%$. The EOM concentration of $0.1 \%$ ensured complete inhibition of the growth of bacteria P. Salmonella on Bismuth-sulfite-GRM based agar.

Due to the well pronounced taste and smell of EOM, the task was to determine the maximum possible content of essential oils in finished meat products based on their organoleptic quality parameters. The results of researches are shown in Figure 3. Samples of cutlets were prepared with different EOM concentration $(0.01 \%, 0.1 \%$ and $1 \%$ by weight of minced meat). Upon reaching culinary (edible) readiness, the samples were evaluated according to the following organoleptic parameters: taste peculiar for this type of product, medicinal aroma, spicy fragrance, pleasant smell, hot taste, sour aftertaste.

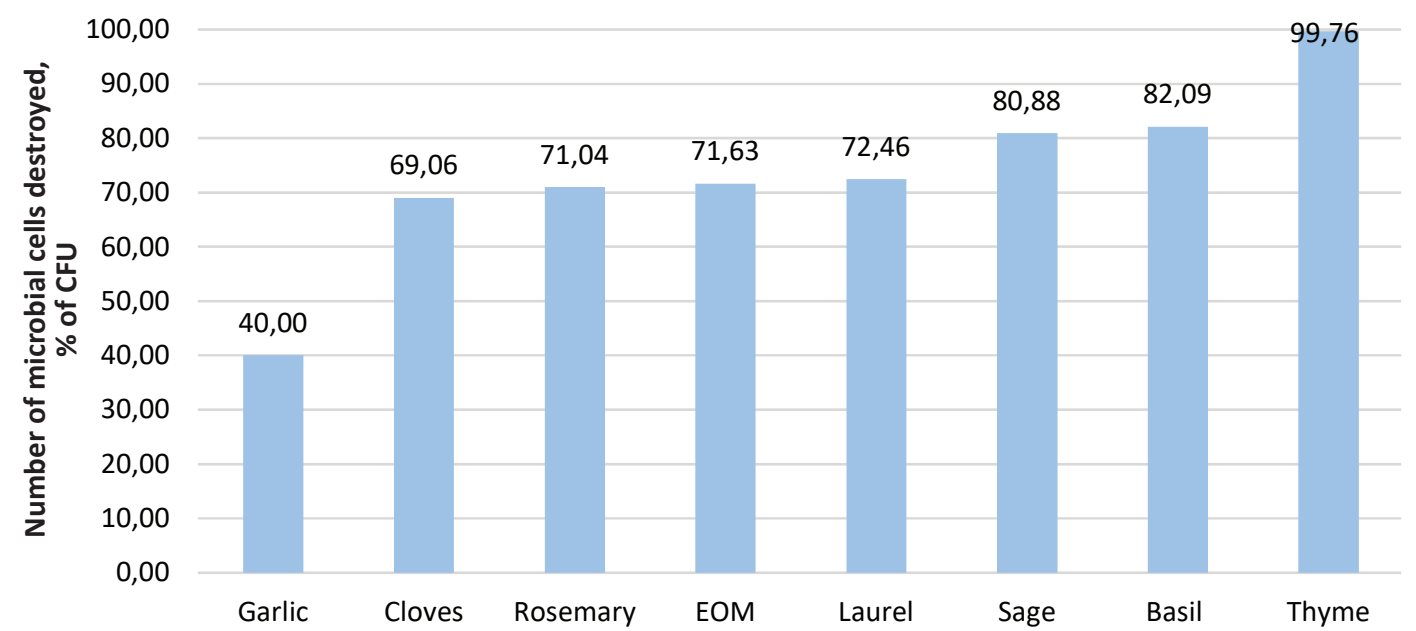

Figure 1. Bactericidal efficiency of essential oils and EOM at concentration of $0.1 \%, \%$ of CFU

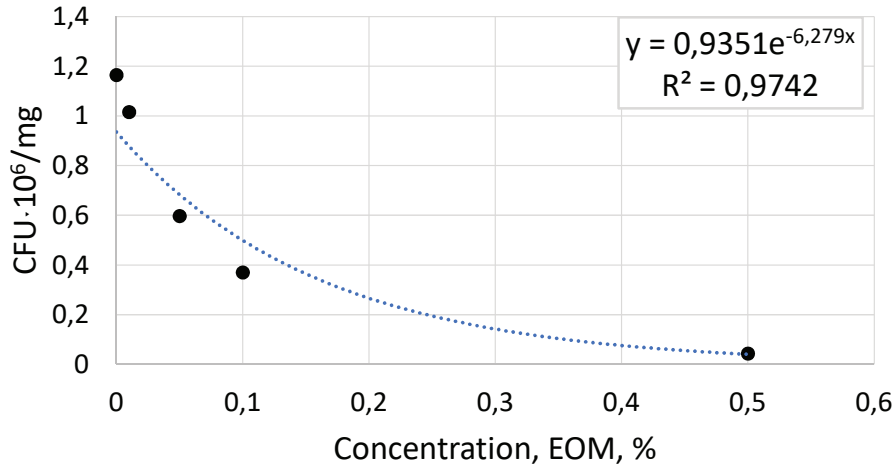

Figure 2. Inhibition of microbial cells by essential-oils mixture

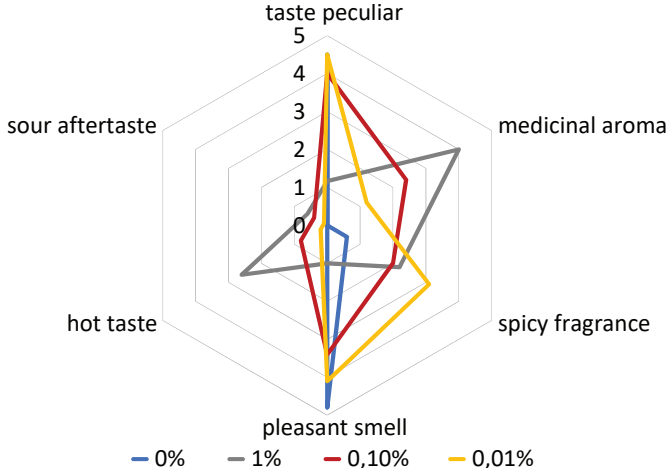

Figure 3. Profilogram of organoleptic parameters of quality 
As can be seen from the data of the profilogram shown above in Figure 3, the samples of cutlets with an EOM concentration in amount of $0.01 \%$ of minced meat weight on the parameter "taste, peculiar for this type of product" were estimated by experts at 4.5 points, which is a good index for the product. This product had a pleasant spicy fragrance (3.1 points), no pronounced medicinal aroma, sour aftertaste and hot taste. In samples with $0.1 \%$ EOM content, the parameter "taste peculiar for this type of product" was estimated at 4 points, which is a satisfactory rating for the product. However, such organoleptic parameters as "medicinal aroma", "hot taste" and "sour aftertaste" were higher than similar parameters of samples with $0.01 \%$ EOM by $50 \%, 25 \%$ and $25 \%$ respectively.

The samples with $1 \%$ concentration of EOM featured by a pronounced medicinal aroma (4 points) and a hot taste (2.6 points). According to the parameter "taste peculiar for this type of product", it was rated at 1.17 points, which is unsatisfactory for the food. Based on the results of the organoleptic evaluation of the quality parameters and indices, it was determined that the threshold concentration of EOM is $0.1 \%$. This concentration is the maximum one, since at this concentration EOM organoleptic quality indices ("taste peculiar for this type of product", "pleasant smell", "spicy fragrance") are considered as satisfactory rating.

Thus, the optimal concentration for conducting experiments was determined to be $0.1 \%$, since at this EOM concentration, optimal inhibition of saprophytic microflora was provided (the residual content is equal to $2.3 \times 10^{5}$ $\mathrm{CFU} / \mathrm{ml}$ ), which corresponds to the safety indices of fresh meat, according to the Unified Sanitary and Epidemiological and Hygienic Requirements for food products (goods) subject to sanitary and epidemiological supervision (control), as well as satisfactory organoleptic indices of quality.

QMAFAnM is important specified parameter of food safety. According to the Unified Sanitary and Epidemiological and Hygienic Requirements for goods subject to sanitary-epidemiological supervision (control), the permissible level of QMAFAnM for small-batch semi-finished products shall not be more than $1 \times 10^{6} \mathrm{CFU} / \mathrm{g}$. No coliforms, pathogenic microorganisms (including salmonella), L. monocytogenes are allowed. Therefore, the changes in the quantitative and qualitative composition of the microflora were further investigated.

At the beginning of the experiment the microflora of meat was represented by the following microorganisms:

- Micrococcus sp.;

- Bacillus sp.;

- Pseudomonas sp.;

- Flavimonas sp.;

- Sphaerotilus sp.

During the first day of storage of control samples a slight decrease in QMAFAnM was observed due to cooling treatment of meat (at a storage temperature of $0{ }^{\circ} \mathrm{C}$ to $4{ }^{\circ} \mathrm{C}$ ) from $4.15 \times 10^{4}$ to $3.1 \times 10^{4} \mathrm{CFU} / \mathrm{g}$ by the $36^{\text {th }}$ hour of storage. After 60 hours of storage the QMAFAnM $\left(3.3 \times 10^{4} \mathrm{CFU} / \mathrm{g}\right)$ increased. By the $84^{\text {th }}$ hour of storage the QMAFAnM in series of control samples exceeded the standard value by 2.3 times. By the $156^{\text {th }}$ hour this parameter exceeded the normalized index by 40 times. QMAFAnM was not measured after that.

In the meat samples with EOM, the significant reduction of lag phase duration, and the rapid onset of the exponential growth phase of microorganisms were observed due to action of essential oils on these samples $(4.15 \times 104$ $\mathrm{CFU} / \mathrm{g}$ at the beginning of the experiment and $4.43 \times 104$ $\mathrm{CFU} / \mathrm{g}$ in 36 hours). The stationary phase of growth is also reduced, as can be seen from the rapid onset of dieoff phase $(1.57 \times 104 \mathrm{CFU} / \mathrm{g}, 60$ hours of storage). Starting from the $60^{\text {th }}$ hours, there is an increase in quantity of microorganisms. However, QMAFAnM did not exceed the standard value by the $84^{\text {th }}$ hour of storage $(2 \times 105 \mathrm{CFU} / \mathrm{g})$ and the $156^{\text {th }}$ hour of storage $(2.2 \times 105 \mathrm{CFU} / \mathrm{g})$. However, in 8.5 days of storage, there was a 1.34-fold excess of the standard QMAFAnM value (Figure 4).

Based on the obtained data it is obvious that the shelf life of the control samples was equal to 60 hours approximately, and the shelf life of the samples with EOM - about 156 hours. Thus, EOM allowed extension of the period of cold storage of semi-finished natural meat lump (cutlet pork) by 2.6 times.

The average time of microorganisms generation on control samples was 9.83 hours, for the samples with EOM 27.59 hours.

Histological studies have shown that use of essential oils mixture slows down autolytic processes. So on the first day of research, the microstructure of the muscle tissue of the prototypes corresponded to the classical course of autolysis with a clearly defined core structure, striation and uniform color. After 36 hours of storage the differences in microstructural changes became more apparent. In the sections obtained from meat stored in a gas environment, the fiber thickness was lower in comparison with the control samples. The fibers of the muscle tissue were smooth, tightly fitting to each other, and in some places there were transverse and slit-like violations of fiber integrity. While in the control sample the fragmentation of individual muscle fibers and sometimes shadow-like coloration of the nuclei were noted (Figure 5).

Further the autolysis process in the control samples ran more intensively in comparison with the samples stored in an essential-oil mixture (Figure 6). By the $84^{\text {th }}$ of storage of the control sample, there was a complete disappearance of the striation of the muscle fibers; the surface of the cut slice of the muscle tissue got a basophilic color. In the loose connective tissue of the superficial fasciae in the perimysium and endomysium, the diffuse overlays were predominantly the rod-shaped microflora. The slices revealed the disintegration of individual fragments into myofibrils, and disintegration of myofibrils into sarcomeres in the form of a granular mass, sometimes enclosed in endomysium. The fibers were deformed and separation of fibers was observed. 

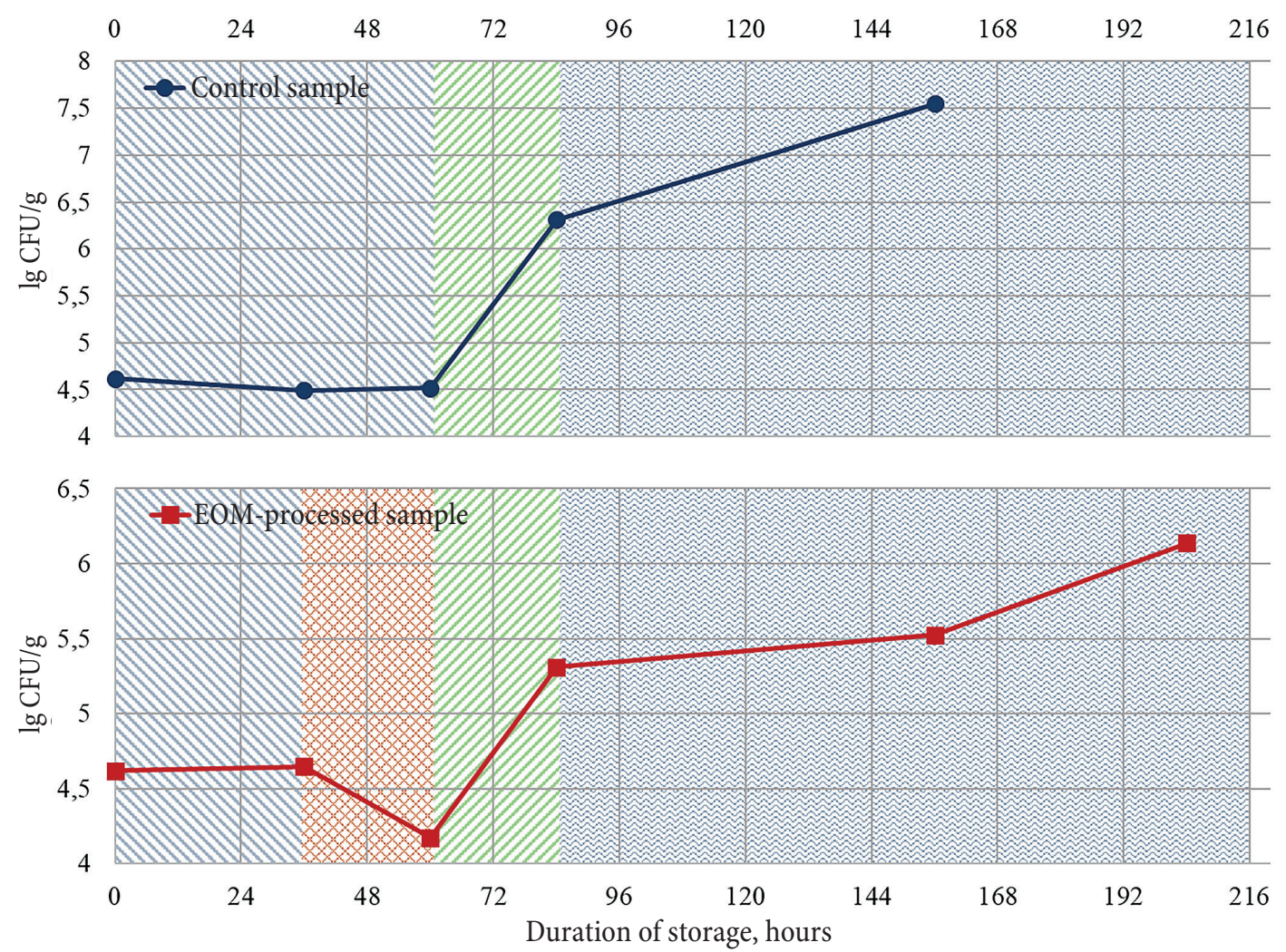

MV - Lag-phase

Figure 4. Change of QMAFAnM in meat during its storage
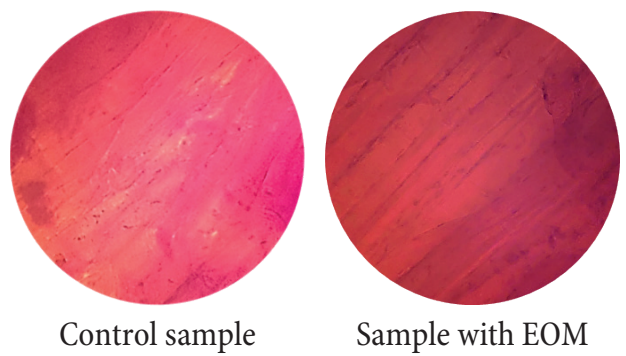

Figure 5. Histological specimen of longitudinal slices of pork cutlet meat after 36 hours of storage

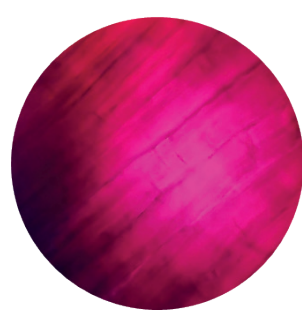

Control sample

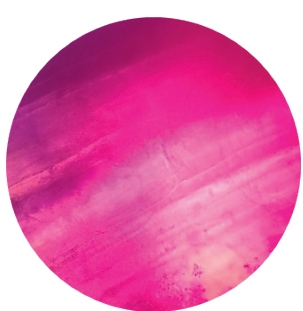

Sample with EOM
Figure 6. Histological specimen of longitudinal slices of pork cutlet meat after 84 hours of storage

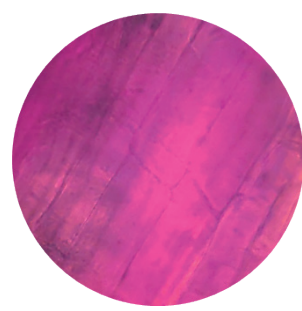

Control sample

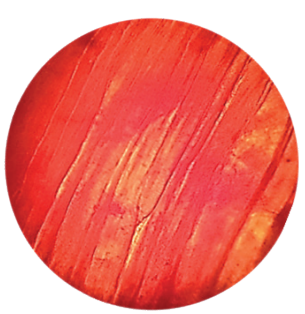

Sample with EOM
Figure 7. Histological specimen of longitudinal slices of pork cutlet meat after 204 hours of storage
Meat has become non-technologically unfeasible and unsuitable for its consumption in terms of safety parameters and indices. Similar changes occurred with samples stored in the EOM by the $204^{\text {th }}$ hour of storage (Figure 7).

The difference in intensity of proteolytic processes was also confirmed by results of study of specific electrical conductivity. Changes in specific electrical conductivity of extracts from muscle tissue (Figure 8) occurred as a result of increase in quantity of charged particles due to the hydrolysis of proteins. Along with the decomposition of highmolecular compounds, the specific electrical conductivity of the control samples increased from $870 \mu \mathrm{S} / \mathrm{cm}$ to 910 $\mu \mathrm{S} / \mathrm{cm}$. The average rate of increase of specific electrical conductivity was $11.5(\mu \mathrm{S} / \mathrm{cm}) /$ day. The further decrease of specific electrical conductivity from the $84^{\text {th }}$ hour of storage of the control sample to $902 \mu \mathrm{S} / \mathrm{cm}$ may be caused by development of microflora, which both actively consumes protein and low-molecular substances, and accelerates the decomposition of high-molecular components, which leads to formation of interionic associates or ion pairs, to increasing of solution viscosity, and to other effects that reduce the mobility of ions and cause decrease of specific electrical conductivity [14].

The higher values of specific electrical conductivity of solutions of aqueous extracts obtained from muscle tissue with EOM compared to the control sample can be explained by the fact that essential oils interact with proteins and lipids of muscle tissue and create an additional electric charge. At the same time, the microflora has only insignificant effect on change of specific electrical conductivity value. The 


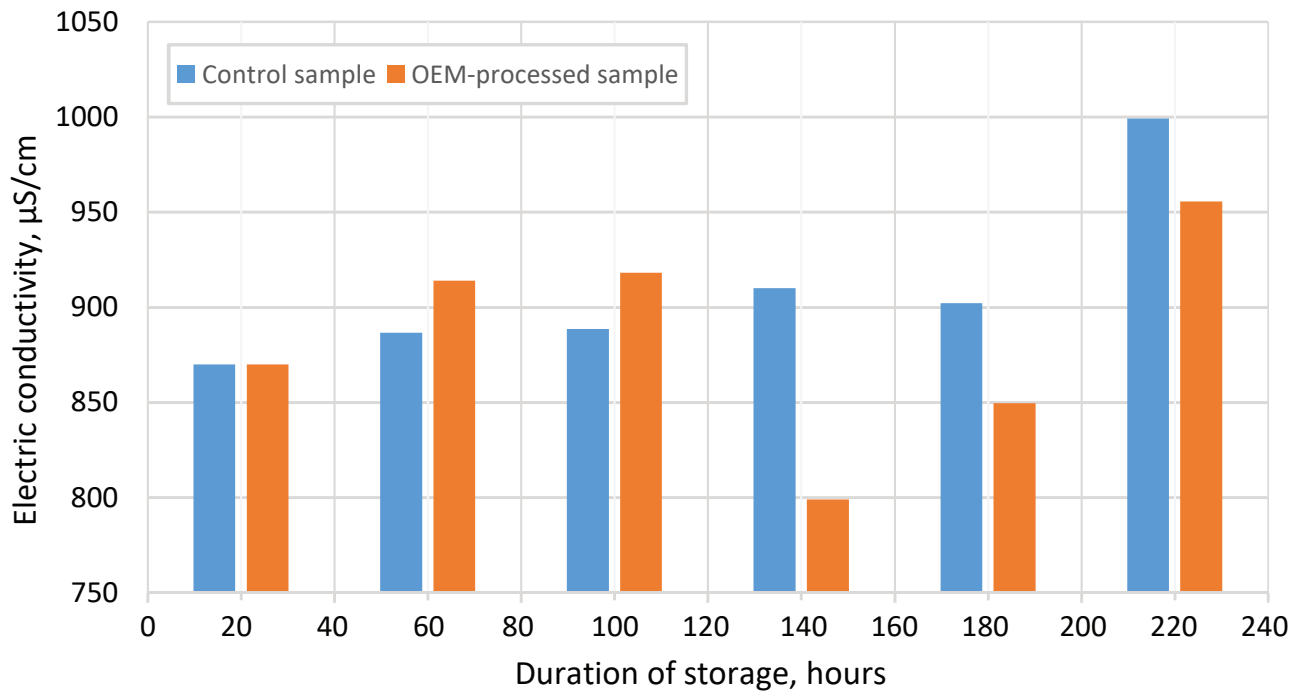

FIgure 8. Change in the value of the specific electrical conductivity of meat samples

subsequent decrease of specific electrical conductivity value (down to $799 \mu \mathrm{S} / \mathrm{cm}$ ) is associated with formation of complex compounds of the essential oils components with proteins and lipids of muscle tissue, which formation results to the cell structures strengthening, as the cells walls become less permeable and more elastic, and the thickness of the muscle fiber slightly reduces in comparison with the control sample. These results are confirmed by studies of histological structural changes which occur in meat. This change of morphological properties of muscle tissue prov+ides a smaller outlet of muscle fibers contents into intercellular space, thereby reducing specific electrical conductivity value [14].

\section{Conclusion}

In result of the conducted studies it is possible to conclude that application of EOM in gas mixture composition at concentration of $0.1 \%$ for the storage of meat semi-fin- ished food products has highly promising prospects, since application of this OEM increases the shelf life of food product by 2.6 times. The analysis of histological structural and electrochemical changes in muscle tissue showed differences in the process of autolysis in meat during its storage in a gas environment with EOM added.

It should also be noted that EOM allows regulation of flavor (taste and smell) properties of meat. However, EOM in composition of gas medium for meat storage must be used along with components that allow regulation of color and strength parameters, as essential oils are able to cause changes in color and texture of a food product, when interacting with proteins and lipids of meat.

Thus, the application of EOM in food systems reduces the amount of synthetic preservatives to be used, and can serve as an alternative solution to meet the growing need of consumers for food safety of meat and meat products.

\section{REFERENCES}

1. WHO (WorldHealthOrganization). (2021) Food safety. Retrieved from https://www.who.int/news-room/fact-sheets/detail/food-safety Accessed March 03, 2021

2. Preedy, V.R. (2015). Essential oils in food preservation, flavor and safety. London: Academic Press. 2015. 930.

3. El Fayoumy, R.A., Abou-Dobara, M.I., Pendleton, P., EL-Fallal, A.A., EL-Sayed, A.K.A. (2019).The Antimicrobial activity of some essential oils against some selected food borne pathogens. International Journal of Scientific \& Engineering Research, 10(2), 237-241. 4. Patial P., Jandaik S., Kumar R., Pathania K., Urmila. (2016). Antimicrobial Evaluation of some Essential Oil Combinations Against Food Borne Pathogens. International Journal of Biology, Pharmacy and Allied Sciences, 5(8), 1953-1964.

5. Mahian, R. A., Sani, A. M. (2016). Essential oils in food systems: A systemic review. International Journal of PharmTech Research, 9(6), 409-416.

6. Helander, I. M., Alakomi, H. -L., Latva-Kala, K., Mattila-Sandholm, T., Pol, I., Smid, E. J. at al. (1998). Characterization of the action of selected essential oil components on gram-negative bacteria. Journal of Agricultural and Food Chemistry, 46(9), 3590-3595. https://doi.org/10.1021/jf980154m

7. Ultee, A., Kets, E. P. W., Smid, E. J. (1999). Mechanisms of action of carvacrol on the food-borne pathogen. Applied and Environmental Microbiology, 65(10), 4606-4610. https://doi. org/10.1128/aem.65.10.4606-4610.1999

8. Ultee, A., Smid, E. J. (2001). Effect of carvacrol on growth and toxin production by bacillus cereus. International Journal of Food
Microbiology, 64(3), 373-378. https://doi.org/10.1016/S01681605(00)00480-3

9. Desoky, H.R., Edris, A.M., Maarouf, A.A., Abdl-Aal, A.M. (2021). Sensory and Antibacterial Impacts of Some Added Essential Oils to Raw Chicken Meat. IOSR Journal of Agriculture and Veterinary Science (IOSR-JAVS),14(2), 2021, 28-32. https://doi. org/10.9790/2380-1402012832

10. Ju, J., Xie, Y., Guo, Y., Cheng, Y., Qian, H., Yao, W. (2019). Application of edible coating with essential oil in food preservation. Critical Reviews in Food Science and Nutrition, 59(15), 24672480. https://doi.org/10.1080/10408398.2018.1456402

11. Esmaeili, H., Cheraghi, N., Khanjari, A., Rezaeigolestani, M. Basti, A. A., Kamkar, A., Aghaee, E. M. (2020). Incorporation of nanoencapsulated garlic essential oil into edible films: A novel approach for extending shelf life of vacuum-packed sausages. Meat Science, 166 https://doi.org/10.1016/j.meatsci.2020.108135 12. Leng, Y., Sun, Y., Wang, X., Hou, J., Zhao, X., Zhang, Y. (2020). Electrical impedance estimation for pork tissues during chilled storage. Meat Science, 161 https://doi.org/10.1016/j.meatsci.2019.108014

13. Engchuan, W., Jittanit, W. (2013). Electrical and thermo-physical properties of meat ball. International Journal of Food Properties, 16(8), 1676-1692. https://doi.org/10.1080/10942912.20 11.604891

14. Polyachenok, O.G., Polyachenok, L.D. (2006). Physical and colloidal chemistry. Minsk: Belarusian State Technical University. 2006. 380. 


\section{AUTHOR INFORMATION}

Aleh U. Shkabrou - Candidate of Technical Sciences, Associate Professor, Dean of the Chemico-technological Faculty, Belarusian State University of Food and Chemical Technologies, Mogilev, Republic of Belarus.

Tel.: +375-292-44-18-89, E-mail: olegshk@tut.by

ORCID: http://orcid.org/0000-0002-7188-2237

* corresponding author

Victar D. Raznichenka - Postgraduate, Belarusian State University of Food and Chemical Technologies, Mogilev, Republic of Belarus. Tel.: +375-259-06-11-53, E-mail: rotcivetec@gmail.com ORCID: http://orcid.org/0000-0002-1537-8482

Lidziya Y. Kharkevich - Graduate student, Belarusian State University of Food and Chemical Technologies, Mogilev, Republic of Belarus. Tel.: +375-333-19-79-99, E-mail: lxarkevich@mail.ru ORCID: http://orcid.org/0000-0002-8377-4321

All authors bear responsibility for the work and presented data.

All authors made an equal contribution to the work.

The authors were equally involved in writing the manuscript and bear the equal responsibility for plagiarism.

The authors declare no conflict of interest.

Received 25.01.2021 Accepted in revised 20.03.2021 Accepted for publication 25.03.2021 